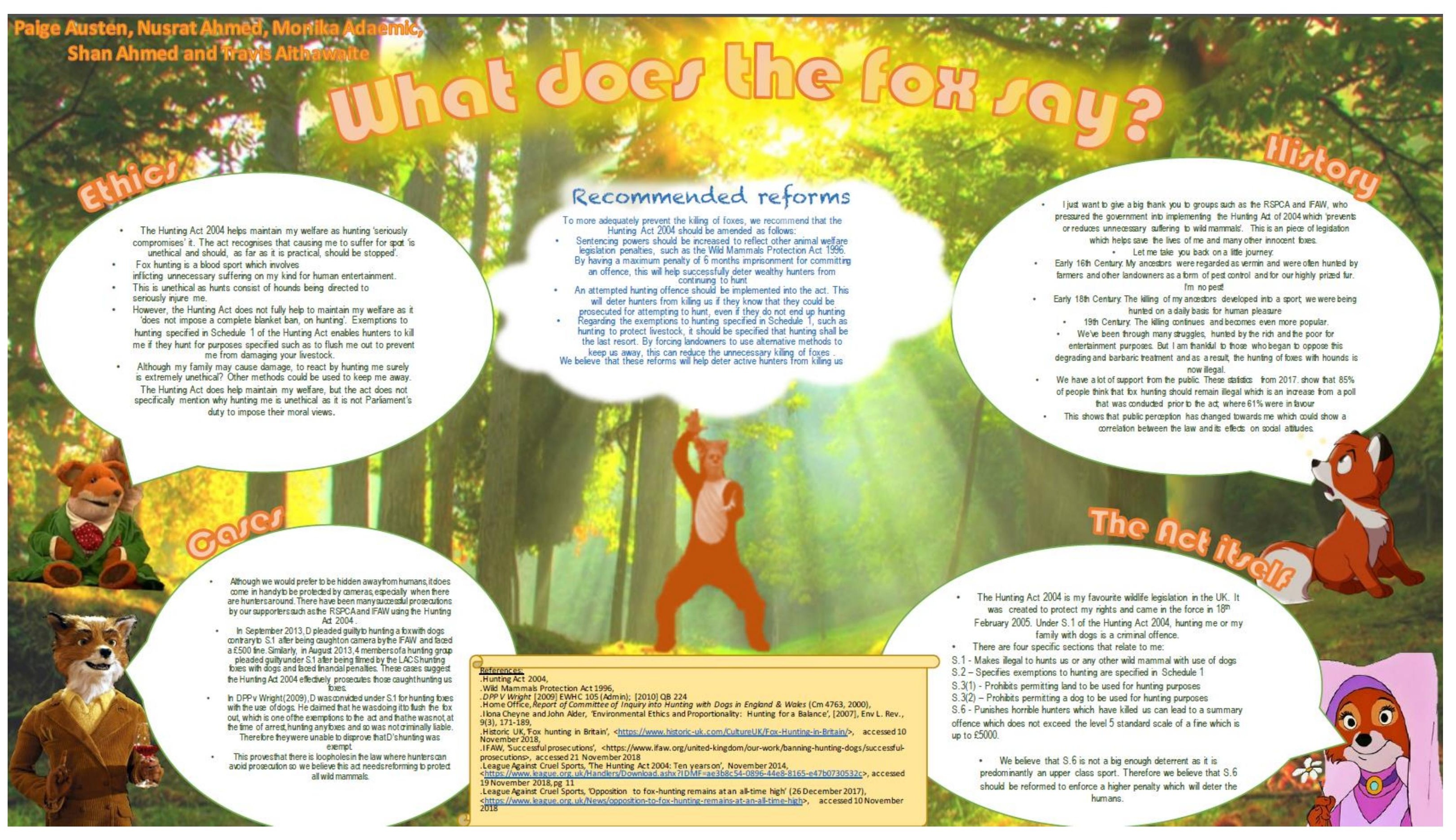




\section{Does the Hunting Act 2004 adequately prevent the killing of foxes?}

Foxes have been hunted for decades in the United Kingdom due to it being an essential part of British culture. However, nowadays the public are strongly against fox hunting. This is evident from The Hunting Act 2004 (Act 04) being enforced to protect wild mammals. Despite the Act being in effect there have been cases where suspected hunters have gotten away with being convicted of hunting as a result of loopholes within the current legislation. Therefore in order to improve the effectiveness of the Act it must be built upon. Through analysing the Act itself alongside cases, ethical issues of hunting and changing social attitudes, we will consider whether the Act can be altered so that it can adequately prevent the killing of foxes.

The Act 04 came into force in February 2005 and became a popular and controversial piece of legislation in the UK. It was influenced by the Scottish law: Protection of Wild Mammals Act 2002. The Act 04 was designed to make chasing and deliberately killing wild mammals with use of dogs illegal (S.1) and to improve wildlife in England and Wales.

The offences are specified in following sections:

S.1 states that a person commits an offence if he hunts a wild mammal with dogs.

S.3 makes it illegal to permit land to be used for hunting and to use dogs for hunting.

S.6 any person found guilty under Act 04 will be subject to penalties. The maximum available penalty is a fine up to $£ 5000^{1}$.

\footnotetext{
${ }^{1}$ Friend V United Kingdom [2009] 11 WLUK 569; (2010) 50 EHRR SE6, at 70 
This research report focuses mainly on fox hunting. As presented in the diagram ${ }^{2}$ it has been influenced by public pressure. Although Act 04 consists of 17 sections, only 4 sections relates to fox hunting which leaves an extensive gap in the law. This suggests that creation of this act was rushed as it does not cover all types of hunting used to kill foxes. Such exemptions to unlawful hunting is specified in S.2 Schedule 1 as follows:

- Flushing out foxes to prevent or reduce serious damage to livestock ${ }^{3}$

- Falconry ${ }^{4}$ (using birds to hunt)

- Rescue of wild mammal ${ }^{5}$

- Research and observation ${ }^{6}$ (hunting for research)

Therefore the Act 04 has contributed towards preventing fox killings as shown by the number of successful prosecutions e.g. 52 people were convicted in $2017^{7}$. However to ensure that Act 04 prevents hunters from avoiding prosecution through loopholes, it must be amended to make the

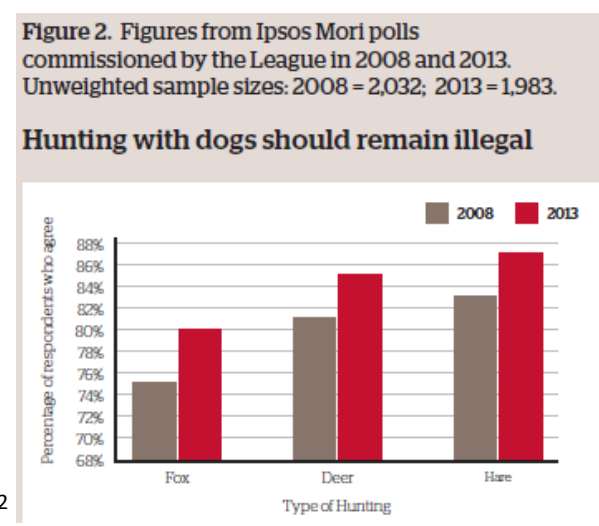

League Against Cruel Sports, 'The Hunting Act 2004: Ten years on', November 2014

<https://www.league.org.uk/Handlers/Download.ashx?IDMF=ae3b8c54-0896-44e8-8165-e47b0730532c> accessed 19 November 2018, pg 11

${ }^{3}$ Hunting Act 2004, Sch 1, para.1

${ }^{4}$ Ibid. para.6

${ }^{5}$ n.3, para.8

${ }^{6}$ n.3, para.9

${ }^{7}$ Parliament UK, Lucy Frazer, <https://www.parliament.uk/business/publications/written-questions-answersstatements/written-question/Commons/2018-06-06/150579/> accessed 19 November 2018 


\section{Volume 1 Issue 1 Student Journal of Professional Practice and Academic Research}

criteria for criminal liability more strict. Furthermore, as hunting is predominantly an upper class sport, the maximum penalty does not effectively prevent fox-hunting as this is not a major deterrent to them because of their wealth. Therefore the punishment for being convicted under Act 04 must be increased. The League Against Cruel Sports (LACS) suggests that sentencing powers should be increased to 'be in line with the Protection of Badgers Act and Wild Mammals Protection Act, with a maximum penalty of six months imprisonment ${ }^{\prime 8}$. This reform to S.6 of Act 04 is reasonable as it would put a bigger deterrent in place to prevent upper class hunters from continuing to kill foxes.

Recent hunting cases have had different outcomes, suggesting that the effectiveness of Act 04 in adequately preventing fox killings varies according to the facts of the case. In a case brought privately by RSPCA in September 2013, D pleaded guilty to hunting a fox with dogs contrary to S.1 after being caught on camera by the IFAW ${ }^{9}$ and faced a $£ 500$ fine. Similarly, in August 2013, 4 members of a hunting group pleaded guilty under S.1 after being filmed by the LACS hunting foxes with dogs ${ }^{10}$ and faced financial penalties. These cases suggest that Act 04 quite effectively prosecutes those caught hunting foxes.

The RSPCA V McCormick [2016] ${ }^{11}$ case suggests that penalties under Act 04 should be increased. D was convicted under the Animal Welfare Act 2006. However, his conviction was dropped using a loophole as to be held liable the dogs had to be in the presence of mammals, which was not the case here. The court stated that the penalty for animal fighting is harsher under the 2006 Act than

\footnotetext{
${ }^{8}$ League Against Cruel Sports, 'Strengthening the Hunting Act', <https://www.league.org.uk/hunting-act> accessed 19 November 2018

${ }^{9} \mathrm{BBC}$, 'Somerset man pleads guilty to hunting fox with dogs', <https://www.bbc.co.uk/news/uk-england24077013> accessed 21 November 2018

${ }^{10}$ IFAW, 'Successful prosecutions', <https://www.ifaw.org/united-kingdom/our-work/banning-huntingdogs/successful-prosecutions> accessed 21 November 2018

${ }^{11}$ RSPCA V McCormick [2016] EWHC 928 (Admin); [2016] 1 WLR 2641
} 
Act 04 as ' $D$ can be imprisoned for up to six months and disqualified from keeping animals for life. Under the Hunting Act, only financial penalties are available, with no risk of disqualification $^{12}$. This suggests that having stricter penalties for hunting will make Act 04 more effective as it will be a stronger deterrent to wealthy hunters.

However, by relying on loopholes and hunting exemptions, hunters can avoid prosecution. In $D P P$ $v$ Wright $[2009]^{13}$, D was convicted under S.1 for hunting foxes with dogs, which he claimed he was doing to flush the fox out, one of the exemptions to hunting. D appealed on the basis that although he may have had the intent to hunt, he was not, at the time of arrest, hunting any foxes and so was not criminally liable. Consequently, the appeal was allowed as the prosecution failed to disprove that D’s hunting was exempt. The literal approach to statutory interpretation allowed D to avoid liability as the wording of 'Stalking a wild animal or flushing it out' ${ }^{\text {' }}$. The Crown Court ruled that 'you do not...stalk an unidentified wild mammal by merely searching for it...the use of the words "it" requires that the wild mammal has been identified"15. Here D had not identified a fox to hunt so his charges were dropped because 'hunting' implies pursuing a fox, which D had not done. It was also said that 'A person who left home intending to search for a fox might in a sense be going hunting, but he was not at that moment hunting because the wild animal had not yet been found, ${ }^{16}$.

This case implies that Act 04 is not fully effective in preventing fox killings because by allowing D’s appeal, the court provided D with another chance to kill foxes. It is evident that attempted

\footnotetext{
12 ibid. At 2647

${ }^{13}$ DPP V Wright [2009] EWHC 105 (Admin); [2010] QB 224

${ }^{14} \mathrm{n} .3$

${ }^{15} \mathrm{n} .13$ at 234

${ }^{16}$ Ibid.
} 
hunting is not a criminal offence under Act 04 which is problematic as it gives hunters a loophole, a chance to avoid conviction in a situation where, if they had not been caught, would have hunted the fox anyways. This gap in Act 04 must be reformed to include an attempted hunting offence. This proposed reform would be likely to work as it will deter hunters from killing foxes if they know they will be held criminally liable for attempting to hunt even if they do not end up hunting.

There are several reasons as to why Act 04 was introduced. Years of pressure from groups such as the RSPCA and IFAW forced the government into implementing an act which would 'prevent or reduce unnecessary suffering to wild mammals ${ }^{17}$.However, farmers and landowners may still protect their livestock by eliminating wild mammals which may be a threat.

Prior to the introduction of the Act, animals such as foxes were regarded as 'vermin' and were often hunted by farmers and other landowners as a 'form of pest control (both to curb their attacks on farm animals and for their highly prized fur) ${ }^{18}$. It wasn't until the eighteenth century where

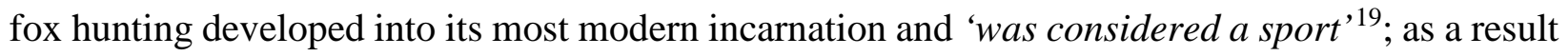
of the decline in the deer population. Foxhunting continued to grow in popularity throughout the nineteenth century. Hunting became associated with kingship where 'large tracts of land were preserved for the king's pleasure as they would hunt a variety of game and even exotic animals imported from abroad ${ }^{20}$. Some historians believe that hunting was critical in displaying royal

\footnotetext{
${ }^{17}$ The Hunting Act for enforcement professionals, 'The Hunting Act', <http://www.huntingact.org/hunting/huntingin-the-uk/> accessed 21 November 2018

${ }^{18}$ Historic UK, 'Fox hunting in Britain', <https://www.historic-uk.com/CultureUK/Fox-Hunting-in-Britain/> accessed 10 November 2018

${ }^{19}$ Ibid.

20 'How did hunting become a symbol of royalty',

<https://dailyhistory.org/How_did_hunting_become_a_symbol_of_the_royalty\%3F> accessed 19 November 2018
} 


\section{Volume 1 Issue 1 Student Journal of Professional Practice and Academic Research}

authority. It was far more than pleasure or sport; it had 'an important social function in establishing not only the kings' power but demonstrating the vitality of the state ${ }^{21}$.

These points above highlights social attitudes towards animals throughout time; prior to the implementation of the Hunting Act. Up until this period, there was no consideration to the welfare of an animal but innocent 'creatures' were merely used as a source of entertainment for a large proportion of society. But since the implementation of the Act, have social attitudes changed? Has the Act been successful in preventing and reducing 'unnecessary suffering to mammals'?

Statistics from a poll conducted in $2017^{22}$ show that $85 \%$ of people think that fox hunting should remain illegal which is an increase from a poll that was conducted prior to the Act, where $61 \%$ were in favor. This shows that public perception has changed slightly and could show a correlation between the law and its effects on social attitudes. However, there are still those who still support the hunting of animals E.G trail hunters; which highlights the inconsistencies within the current law. Trail hunters mimic traditional hunting by 'following an animal-based scent trail which has been laid in areas where foxes or hares are likely to $b e^{, 23}$ and use this as a grey area around the law. Recent news reports ${ }^{24}$ show that many hunters can get around the Act by replicating live quarry hunting to allow huntsman to train hounds on animal-based scents in anticipation that the

\footnotetext{
21 Ibid.

${ }^{22}$ League Against Cruel Sports, ‘Opposition to fox-hunting remains at an all-time high’ (26 December 2017), <https://www.league.org.uk/News/opposition-to-fox-hunting-remains-at-an-all-time-high> accessed 10 November 2018

${ }^{23}$ League against Cruel Sports, 'Trail hunting - the truth', <https://www.league.org.uk/trail-hunting> accessed 10 November 2018

${ }^{24}$ Mattha Busby (26 ${ }^{\text {th }}$ December 2017), 'Fox hunting: activists claim trail-hunts are a cover for continued blood sport', <https://www.theguardian.com/uk-news/2017/dec/26/fox-hunting-activists-claim-trail-hunts-are-a-cover-forcontinued-bloodsport> accessed 21st November 2018
} 
Act 04 will eventually be repealed, and if they come across a fox by accident then they are not liable.

Others that support the hunting of animals include high-profile figures such as Theresa May, who recently attempted to legalise fox hunting. This could show a link between social backgrounds and their attitudes in society. It is apparent that those who are pro-hunters are mostly from upper-class backgrounds and in previous decades were the ones that hunted for daily entertainment E.G Kings and Dukes.

So, the Act has been successful in reducing the amount of people that kill foxes, however it has not successfully prevented hunting which is evident as foxes are still being hunted by trail hunters. This could be because the Act has not been successful in changing social attitudes and therefore it will never be fully effective until social attitudes change. Whilst most of the public are against fox hunting the attitudes of the upper class have supposedly not changed, as evident in the number of prosecutions each year ${ }^{25}$.

The ethical issue which surrounds fox hunting is maintaining animal welfare. As YouTube videos $^{26}$ provides guidance on how to hunt while avoiding the law, this suggests that Act 04 requires more restrictions to reduce fox killing. In the report following the Burns Inquiry, a government inquiry set up to discuss hunting with dogs, the committee found that hunting foxes with dogs 'seriously compromises the welfare of the fox ${ }^{27}$. Anti-hunting groups, such as the LACS, discourages hunting because it is a blood sport. During hunts, foxes suffer death from the

\footnotetext{
${ }^{25} \mathrm{n} .7$

26 YouTube, 'How to break the hunting act and get away with it', $<$ https://www.youtube.com/watch?v=iNHrLWiqxqk> accessed 21 November 2018

${ }^{27}$ Home Office, Report of Committee of Inquiry into Hunting with Dogs in England \& Wales (Cm 4763, 2000) para 56
} 
infliction of serious injuries from hounds. Recent statistics ${ }^{28}$ on public opinions of hunting corroborates the view that fox-hunting is unethical because it causes unnecessary suffering.

A problem that Act 04 presents is that it does not impose a complete ban on hunting, as schedule 1 of the Act provides nine exemptions. This can be explained by the fact that the statutory aim of the Act 04 is 'to prevent or reduce unnecessary suffering to wild mammals' and that 'causing suffering to animals for sport is unethical and should, so far as practicable and proportionate, be stopped $^{29}$. As schedule 1 highlights the practical aspects of exempt hunting, such as pest control, 'the exemptions seem to dilute the ethical standpoint of the Act with a utilitarian element' ${ }^{30}$. This view is reasonable as the Burns inquiry was not set up to 'consider moral or ethical issues ${ }^{31}$ of hunting. The main purpose was to explore the practical aspects of hunting regarding the rural economy, countryside culture and the management of wildlife ${ }^{32}$. This suggests that Parliament did not consider it reasonable to explore the ethical issues of hunting in detail in the Act ${ }^{33}$. This implies that The Hunting Act does not adequately prevent the killing of foxes as it does not fully emphasise the importance of protecting foxes from harm. Rather the exemptions seem to promote an increase in using different methods to kill foxes such as trail hunting. On the other hand, the idea that the Act does not focus solely on enforcing the ethical implications of fox-hunting is beneficial as the role of the Parliament is to create legislation without imposing their own moral values into it. ${ }^{34}$

\footnotetext{
${ }^{28}$ n. 22

${ }^{29}$ n.2, at pg 5

${ }^{30}$ Ilona Cheyne and John Alder, 'Environmental Ethics and Proportionality: Hunting for a Balance', (2007) 9(3), Env L. Rev. 171, 174

${ }^{31} \mathrm{n} .27$, at para 2

32 ibid.

${ }^{33}$ n.30 at 183

${ }^{34}$ n. 30 , at 188
} 
The exemptions to hunting are reasonable as protecting livestock is essential for farmers to make their livelihood.

However, in order to adequately prevent the killing of foxes, a compromise should be implemented in the Act 04 between the utilitarian aspect of hunting foxes and the ethical value of preventing fox cruelty. Farmers who want to protect their livestock from foxes should ensure that alternative methods are used to keep foxes away. The LACS suggest that secure electric fences can be used to protect livestock ${ }^{35}$.This alternative may ensure that animal cruelty is reduced, thus fulfilling the statutory aim of the hunting act.

To conclude, the Act 04 is an effective law as there were 52 successful prosecutions in $2017^{36}$. IFAW has contributed to this by filming the hunts which has acted as a deterrent ensuring that people abide by the law ${ }^{37}$. However, the burden of proof is difficult because cases require video footage where a fox is in plain sight and the hounds are being encouraged by the huntsman to hunt by not calling the hounds back or sounding the horn, which makes it difficult to even stand a chance for a prosecution.

Also there are still issues with enforcement as loopholes in Act 04 are consequently exploited so people can avoid prosecution. In order for Act 04 to adequately prevent the killing of foxes the Act needs to be amended to lessen exploitation of the Act. Recommended amendments include: making attempted hunting unlawful as this is not specified in Act 04; make the penalties stricter and to re-write hunting exemptions (s.2) while removing the research and observation exemption.

\footnotetext{
${ }^{35}$ League Against Cruel Sports, 'Fox-Hunting', <https://www.league.org.uk/fox-hunting> accessed 10 November 2018

${ }^{36}$ n.7

${ }^{37}$ n. 10
} 
These reforms are essential as stricter criteria for criminal liability and higher penalties may help to deter those who actively partake in hunts. 